\title{
Nietzsche contra Haeckel
}

\author{
Wilson Antonio Frezzatti Jr.
}

Resumo: Nas poucas referências explícitas de Nietzsche ao biólogo alemão Ernst Haeckel, há uma clara rejeição de seu pensamento biológico e cultural. O objetivo deste artigo é propor que, apesar da pequena quantidade de citações diretas, os ataques de Nietzsche a Haeckel constituem um intenso antagonismo entre eles e inserem-se no contexto das críticas nietzschianas contra a formação (Bildung) e a cultura (Kultur) alemãs e contra a condição metafísica da ciência. $\mathrm{O}$ texto apresenta quatro aspectos do antagonismo entre Nietzsche e Haeckel: das Darwinismus de Haeckel; a influência de Haeckel sobre David Strauss; a inclusão do evolucionismo científico no currículo na Alemanha; e o conflito entre Ludwig Rütimeyer e Haeckel.

Palavras-chave: Darwinismus, David Strauss, Desenvolvimento, Ernst Haeckel, Ludwig Rütimeyer.

* Universidade Estadual do Oeste do Paraná (UNIOESTE), Toledo, Paraná, Brasil.

ORCID https://orcid.org/0000-0002-7519-3789

Correio eletrônico: wfrezzatti@uol.com.br 
Haeckel aparece explicitamente na obra nietzschiana em alguns poucos fragmentos póstumos: Nachlass/FP 1875, 12 [22], KSA 8.257; 1880/1881, 8 [68], KSA 9.397; 1881, 11 [249] e [299], KSA 9.536 e 556; e 1884, 25 [403], KSA 11.117. Todos esses cinco textos são referências claramente negativas ao biólogo alemão. Nietzsche, sem sombra de dúvida, rejeitava as teorias biológicas e sociais de Haeckel. Queremos mostrar neste artigo que, apesar de tão poucos indícios explícitos, há um profundo antagonismo entre os dois autores, enraizado já no período que o filósofo alemão foi professor na Basileia (1869-1879). ${ }^{1}$ Assim, apontamos quatro aspectos das críticas nietzschianas contra Haeckel: o darwinismo de Haeckel (das Darwinismus); a influência de Haeckel sobre David Strauss; a inclusão do evolucionismo científico no currículo na Alemanha; e o conflito entre Ludwig Rütimeyer e Haeckel.

\section{O contexto intelectual de Haeckel}

O médico e o zoologista alemão Ernst Haeckel, professor na Universidade de Jena, é bastante conhecido por ser "o grande campeão de Darwin na Alemanha"² e pela formulação da lei biogenética, ou seja, a ontogenia recapitula a filogenia. ${ }^{3}$ No entanto, sua atuação não se

1 Embora não tenhamos nos baseado neles, mencionamos que Emden (2014, p. 96, 99-100, 138-139, 147-148, 179-180 e 189-191) e Moore (2002, p. 2-3, 26-27, 40-41 e 89-95) também abordaram alguns aspectos da relação entre Nietzsche e Haeckel.

2 A maioria das informações sobre o contexto intelectual de Haeckel foi retirada de Richards, 2008, XVII-6.

3 Há uma polêmica sobre quem teria sido o primeiro biólogo a propor a lei biogenética, se Haeckel ou Fritz Müller. Johann Friedrich Theodor Müller imigrou para o Brasil em 1852 devido a problemas políticos ligados às revoltas de 1848, e estabeleceu-se na colônia alemã de Blumenau, tendo obtido a naturalização brasileira. Entre 1865 e 1867, foi professor de matemática no Liceu do Desterro, atual Florianópolis. Quase foi fuzilado durante a revolta da armada de 1893. Seu livro Para Darwin (Für Darwin, 1864) foi publicado em inglês em 1869, com organização do próprio Charles Darwin, com quem manteve intensa correspondência (cf. Lacerda, 1899, p. 276-277 e Fontes; Hagen, 2009, p. 277-279). Haeckel (1866, p. 295-305), em sua descrição da lei biogenética em Morfologia geral, não menciona a contribuição de Müller. Ao menos em As maravilhas da vida (1904), reconhece a importância de Müller ao conceito: “Como já mostrou o excelente Fritz Müller-Desterro, em seu

304 | Cad. Nietzsche, Guarulhos/Porto Seguro, v.42, n.1, p. 303-328, janeiro/abril, 2021. 
resume a isso, sua produção foi enorme e muito intensa, sendo, segundo

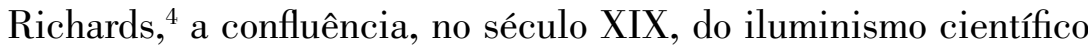
e do pensamento romântico alemães. Entre suas contribuições à biologia, destacam-se a identificação de milhares de novas espécies, o estabelecimento do Reino dos Protistas, a elucidação do núcleo celular como local do material genético, a descoberta do processo de gastrulação na embriogênese, a articulação entre várias áreas da biologia e a criação do termo ecologia e de muitos outros, alguns usados ainda hoje. Não apenas converteu as mentes ao evolucionismo ao redor do mundo, mas é um dos grandes responsáveis pela forte polarização entre o evolucionismo e a religião. $\mathrm{O}$ embate entre essas correntes provavelmente não teria sido tão severo sem os textos de Haeckel, nem o evolucionismo teria recebido um tom tão materialista e ateu. ${ }^{5}$ Ao propor sua filosofia biológica, Haeckel também tinha preocupações sociais e políticas, o que lhe fez abordar as implicações do darwinismo no desenvolvimento ${ }^{6}$ humano, mesmo antes do próprio Darwin fazer isso. As ilustrações de seus trabalhos geralmente eram feitas por ele mesmo, com muita qualidade, publicando em 1904 Formas artísticas da natureza ${ }^{7}$ com dezenas de ilustrações das formas básicas dos seres vivos, desde radiolários a aves, o que o

célebre pequeno escrito Para Darwin [Für Darwin] (1864), a classe dos crustáceos fornece a prova mais evidente para a teoria da seleção e da descendência, para a hereditariedade progressiva* e para a lei fundamental biogenética" (Haeckel, 1924, p. 265). Roux (1881, p. 57, por exemplo), por sua vez, em A luta das partes, ao mencionar os criadores do princípio de biogenia ou filogenia, sempre o atribui a Müller e Haeckel, nessa ordem.

(*) Hereditariedade progressiva: Transmissão aos descendentes não apenas das características recebidas dos ancestrais, mas também daquelas adquiridas pelo indivíduo em vida.

4 Cf. Richards, 2008, p. XVII.

5 Cf. Richards, 2008, p. 14-15.

6 Ao falar dos biólogos contemporâneos a Nietzsche, preferimos o termo "desenvolvimento" a "evolução", pois era o termo utilizado pelos biólogos e naturalistas de meados do século XIX. A palavra evolution foi proposta por Herbert Spencer, passando a ser largamente utilizada antes do fim do século XIX (cf. Spencer, 1864, p. 133 (nota) e 1867, p. 285-286).

7 Título original: Kunstformen der Natur.

Cad. Nietzsche, Guarulhos/Porto Seguro, v.42, n.1, p. 303-328, janeiro/abril, 2021.| 305 
Frezzatti Jr., W. A.

liga à morfologia de Goethe. Ele foi também um profícuo escritor de divulgação do darwinismo e de sua própria filosofia biológica monista. Tanta atividade, muitas vezes provocadora, não poderia ter sido feita sem o surgimento de fortes resistências e críticas, o que inclui acusações de fraude e processos por calúnia. Um exemplo que diz respeito diretamente ao nosso assunto é a denúncia de fraude feita pelo zoólogo suíço Ludwig Rütimeyer em 1868, a qual impingiu a Haeckel uma marca de desonestidade pelo resto da vida. Se o fisiologista Max Verworn, que foi seu aluno, afirmou em um artigo da Zeitschrift für allgemeine Physiologie de 1921: “[Haeckel] não foi somente o último grande herói da era clássica do darwinismo, mas um dos maiores naturalistas pesquisadores de todos os tempos e também um grande e honorável homem", ${ }^{8}$ o neokantiano Erich Adickes dizia que seu Os enigmas do mundo ${ }^{9}$ (1895-1899) era uma pseudofilosofia. O também neokantiano Friedrich Paulsen, em Philosophia militans: contra o clericalismo e o naturalismo ${ }^{10}$ (1901), diz sobre o mesmo livro: "Eu li esse livro com vergonha ardente, com vergonha da condição da educação geral e da educação filosófica de nosso povo. Que tal livro fosse possível, que poderia ser escrito, impresso, comprado, lido, admirado, acreditado por um povo que produziu um Kant, um Goethe, um Schopenhauer - isso é dolorosamente triste". ${ }^{11}$ Em sua época, o biólogo alemão foi acusado por religiosos de arrastar a humanidade à degradação e ao desespero. ${ }^{12}$ Ainda hoje, Haeckel é criticado. O biólogo americano Stephen Jay Gould, em Ontogenia e

8 Verworn apud Richards, 2008, p. 6-7.

9 Título original: Die Welträthsel.

10 Título original: Philosophia militans: Gegen Klericalismus und Naturalismus.

11 Paulsen apud Richards, 2008, p. 7.

12 Essa crítica foi feita pelo não conformista* Robert Forman Horton, no artigo "Ernst Hackel's Riddle of the universe", no periódico Christian World Pulpit 63, 1903 (cf. Richards, 2008, p. 7).

(*) Movimento protestante inglês dissidente do Anglicanismo.

306 | Cad. Nietzsche, Guarulhos/Porto Seguro, v.42, n.1, p. 303-328, janeiro/abril, 2021. 
Filogenia $^{13}$ (1977), acusa-o de produzir um misticismo irracional. ${ }^{14}$ Daniel Gasman, historiador americano, em As origens científicas do Nacional-Socialismo ${ }^{15}$ (1971), afirma que o darwinismo social haeckeliano é uma das mais importantes causas do estabelecimento do pensamento nazista. ${ }^{16} \mathrm{E}$, entre os seus vários críticos de diversas áreas, por vários motivos, encontra-se Nietzsche.

\section{Das Darwinismus: o darwinismo de Haeckel}

Por volta de 1864, as ideias de Darwin encontraram enorme recepção na Alemanha, especialmente em um meio no qual um criticismo contra a Bíblia e um certo materialismo se misturavam. ${ }^{17}$ Formou-se uma doutrina que se chamava Darwinismus, e um dos maiores responsáveis por essa recepção das ideias de Darwin e de seus aliados foi Haeckel. ${ }^{18}$

Em uma carta a Haeckel de 09 de março de 1864, Darwin diz: "Eu estou muito contente que um naturalista tão ilustre confirme $\&$ exponha meus pontos de vista, e posso ver claramente que você é um dos poucos que entende claramente a Seleção Natural". ${ }^{19} \mathrm{O}$ biólogo alemão considerava que a importância da obra de Darwin estava principalmente por, pela primeira vez, introduzir uma explicação

13 Título original: Ontogeny and Phylogeny.

14 Gould, 1977, p. 77-78.

15 Título original: The scientific Origins of National Socialism: Social Darwinism in Ernst Haeckel and the German Monist League.

16 Cf. Richards, 2008, p. 5-6 e Gasman, 2017.

$17 \mathrm{O}$ uso de sua obra por materialistas era motivo de sérias preocupações por parte de Darwin. $\mathrm{O}$ medo de ver suas ideias envolvidas com reformas radicais da sociedade e com críticas à moral e à religião vigentes fazia com que o naturalista inglês escolhesse com extremo cuidado seus tradutores alemães (Cf. Desmond; Moore, 1995, p. 549).

18 Embora não tenha tanto destaque quanto Haeckel, um professor de Bonn, Wilhelm Preyer, também exerceu grande importância na difusão do Darwinismus em fins da década de 1860 (Cf. Desmond; Moore, 1995, p. 582).

19 Darwin, 2018. 
Frezzatti Jr., W. A.

físico-química nos processos vitais: a seleção natural. O subtítulo de sua obra capital, Morfologia geral (1866), é: Elementos gerais da ciência das formas orgânicas, fundada mecanicamente por meio da teoria reformada de C. Darwin sobre a descendência. ${ }^{20}$ No prefácio dessa obra, Haeckel impõe-se a tarefa de desenvolver a ciência dos organismos no âmbito causal-mecânico dos processos inorgânicos, seguindo o mote de Hermann von Helmholtz, declarado no simpósio dos naturalistas alemães em Innsbrück em 1869: “O alvo último das ciências naturais é encontrar de todas as mudanças os movimentos a elas subjacentes e as suas forças impulsoras, portanto reduzi-las à mecânica". ${ }^{21}$

Apesar dessa aproximação tão radical ao pensamento darwiniano, é possível questionar o quanto realmente Haeckel segue o naturalista inglês. O biólogo e filósofo da biologia escocês Edward S. Russell, em Forma e função ${ }^{22}$ (1916), pensava que o principal livro teórico de Haeckel, Morfologia geral, representava mais o pensamento pré-darwiniano que o darwiniano. ${ }^{23}$ Gavin de Beer, embriologista inglês, em Embriões e ancestrais $^{24}$ (1940), acusava o biólogo alemão de ter colocado entraves à embriologia, o que teria atrasado o desenvolvimento da biologia: "Estamos livres de uma camisa-de-força mental que teve efeitos lamentáveis sobre o progresso biológico. Não é exagero dizer que a teoria da recapitulação de Haeckel frustrou e atrasou a introdução de métodos analíticos

20 Título original: Generelle Morphologie der Organismen: Allgemeine Grundzüge der organischen Formen-Wissenschaft, mechanisch begründet durch die von C. Darwin reformirte Descendenz-Theorie. Teoria da descendência era o nome que o próprio Darwin dava a sua teoria.

21 Helmholtz apud Mayr, 1998, p. 138. Em alemão: "Endziel der Naturwissenschaften ist, die allen anderen Veränderungen zugrundeliegenden Bewegungen und deren Triebkräfte zu finden, also sie in Mechanik aufzulösen".

22 Título original: Form and Function: A Contribution to the History of Animal Morphology.

23 Cf. Russell, 1916, p. 249-260.

24. Título original: Embryos and Ancestors.

308 | Cad. Nietzsche, Guarulhos/Porto Seguro, v.42, n.1, p. 303-328, janeiro/abril, 2021. 
causais na embriologia". ${ }^{25} \mathrm{O}$ historiador da biologia Peter Bowler, em $A$ revolução não darwiniana ${ }^{26}$ (1988), entende que justamente a lei biogenética ilustra o caráter não darwiniano do evolucionismo haeckeliano. ${ }^{27}$ Parte dessas críticas pode ser explicada pelo modo paradoxal ou no mínimo curioso com o qual Haeckel descreve sua própria teoria da descendência. Embora o biólogo alemão considere a seleção natural e a luta pela existência como a explicação mecânica para o desenvolvimento, isto é, como o fundamento físico-químico da vida, ele utiliza a adaptação direta e a transmissão dos caracteres adquiridos quando precisa detalhar o mecanismo de desenvolvimento, não lançando mão da seleção de variações produzidas ao acaso. Uma justificativa para isso talvez seja que Haeckel utilize os conceitos darwinianos mais em sua Filosofia biológica do que na Biologia especial. O termo Biologia, insiste o biólogo, deve ser aplicada ao conjunto das ciências orgânicas, com duas grandes divisões: a) Biologia geral ou Filosofia biológica: o papel de toda filosofia verdadeira é englobar e interpretar todos os resultados gerais das pesquisas científicas; e b) Biologia especial: uma sistemática que faz um agrupamento racional de todos os seres vivos e estuda os fatos empíricos que a filosofia agrupa. ${ }^{28}$

O Darwinismus de Haeckel é um dos alvos dos ataques de Nietzsche. No texto preparatório ao parágrafo 224 de Humano, demasiado humano I, o filósofo finaliza suas críticas à luta pela existência e à seleção natural com uma censura ao biólogo alemão (cf. Nachlass/FP 1875, 12 [22], KSA 8.257). O título desse fragmento é "Sobre o darwinismo [Darwinismus]", porém, no texto publicado, no qual se torna o primeiro aforismo do capítulo quinto ("Sinais de cultura

25 De Beer, 1940, p. 97.

26 Título original: The Non-Darwinian Revolution.

27 Cf. Richards, 2008, p. 4-5.

28 Cf. Haeckel, 1924, p. 89-92. 
Frezzatti Jr., W. A.

superior e inferior"), intitula-se "Enobrecimento por degeneração". Além da mudança de título, a crítica a Haeckel foi retirada. ${ }^{29}$

No início do fragmento póstumo, aparece a primeira fase da proposta darwiniana para o surgimento da moral: quanto mais solidariedade e afetos de compaixão ou simpatia tem um homem, mais ele contribuirá com a conservação da linhagem (Stamm) ${ }^{30}$ Com isso, obter-se-iam os costumes adequados, a subordinação do indivíduo à sociedade e a firmeza de caráter. Mas também, acrescenta Nietzsche, haveria o grande perigo da estabilidade e da estupidificação. E é do mais precário e do mais débil que o progresso (Fortschritt) ${ }^{31}$ dependeria: por vezes, eles instauram uma fraqueza no elemento estável, o que possibilitaria o surgimento de algo novo que poderia ser assimilado pelo corpo inteiro sem causar desagregação. Assim, as naturezas degeneradas seriam de enorme importância para a mudança, pois, na grande maioria das vezes, uma perda ou degeneração implicaria vantagem em outra parte. Por outro lado, as naturezas mais fortes fixariam o tipo e o conservariam. A conclusão de Nietzsche: a luta pela existência, a qual o filósofo alemão pressupõe como a vitória do mais forte, não seria o principal princípio do desenvolvimento (Entwicklung), já que é a degeneração, e não o tipo forte, que permitiria a progressão (Fortschreiten). O tipo forte promoveria a conservação. A assimilação do novo é possível com a degeneração ou com o sofrimento de uma parte, se o conjunto se mantiver forte. Isso vale tanto para um indivíduo quanto para uma cultura.

O darwinismo, reafirma o filósofo alemão, é contrário à doutrina do enobrecimento por degeneração. Não apenas isso: Nietzsche

29 Encontra-se, no fim de MA I/HH I 224 (KSA 2.192-193), uma referência a Maquiavel, na qual Nietzsche conclui que a função do Estado é a duração, o que possibilita o enobrecimento por degeneração.

30 Sobre a teoria darwiniana do surgimento da moral, cf. Darwin, 1871, p. 70-106.

31 Em MA I/HH I 224 (KSA 2.189-193), o foco principal de Nietzsche é a progressão espiritual (geistige Fortschreiten).

310 | Cad. Nietzsche, Guarulhos/Porto Seguro, v.42, n.1, p. 303-328, janeiro/abril, 2021. 
alerta que quer se manter junto aos seres humanos e não transpor as leis sobre o enobrecimento humano (Gesetzen über die menschliche Veredlung) ao desenvolvimento animal, pois, caso isso fosse permitido, chegaríamos a sistematizar como bestas os homens, "como fazem o Sr. Haeckel em Jena e seus iguais, como D. Strauss" (Nachlass/FP 1875, 12 [22], KSA 8. 257). ${ }^{32}$

Mas talvez seja a filosofia biológica monista de Haeckel a grande responsável pelas qualificações de mística e romântica dirigidas por muitos contra seu pensamento. Como já dissemos acima, o Darwinismus não se preocupava apenas com os aspectos biológicos do desenvolvimento, mas também com as questões sociais e políticas. Mas não só isso: segundo Richards, ${ }^{33}$ Haeckel via a Origens das espécies (1859) de Darwin como um chamado religioso. O Monismo era, ao mesmo tempo, um darwinismo aplicado e um evolucionismo romântico, que atraiu muitos intelectuais, tais como o inglês Edward Aveling (genro de Marx e tradutor do Das Kapital), o teólogo David F. Strauss, o físico Ernst Mach e a bailarina Isadora Duncan.

Haeckel caracteriza sua filosofia monista como um hilozoísmo, com as metas de buscar um princípio único da natureza e englobar todas as ciências. ${ }^{34}$ A natureza é tudo o que pode ser conhecido, e a essência do Universo é um eterno vir-a-ser. As especulações metafísicas são produtos da imaginação, não sabemos se além da natureza há algo: os conceitos metafísicos surgem porque a imaginação cobre as lacunas de nosso conhecimento. Assim, as atividades psíquicas superiores do homem são funções fisiológicas do cérebro. O Monismo propõe uma única substância com três atributos: matéria, energia e sensibilidade. Todos os corpos naturais são sensíveis - os vivos e os não vivos. A esses três atributos é

32 Aqui Nietzsche parece separar o homem do mundo, o que não será a marca de sua filosofia madura. Talvez esse seja o motivo de as últimas considerações do fragmento póstumo não terem sido publicadas.

33 Cf. Richards, 2008, p. 10-11.

34 Cf. Haeckel, 1924, p. 92-105. 
Frezzatti Jr., W. A.

aplicada a lei da conservação: as quantidades de matéria, energia e sensibilidade no Universo são constantes. Dessa forma, Haeckel constitui a trindade monista da substância: não há matéria sem energia e sensibilidade; não há energia sem matéria e sensibilidade; e não há sensibilidade sem matéria e energia. Portanto, sua filosofia biológica monista não recusa Deus, mas transforma o modo de entendê-lo. ${ }^{35} \mathrm{O}$ deus pessoal e antropomorfizado do dualismo metafísico e supersticioso é substituído pelo panteísmo: Deus e natureza são inseparáveis. O Monismo de Haeckel une a religião e a ciência. ${ }^{36}$

A filosofia monista de Haeckel, todavia, só seria sistematizada em livros após a crise de Nietzsche, isto é, a partir de 1892. Nesse ano, o biólogo alemão publica uma conferência ministrada na Sociedade Naturalista de Osterland, que recebeu inúmeras edições: $O$ monismo como ligação entre religião e ciência ${ }^{37}$ Depois desenvolve seu monismo em Os enigmas do mundo e em As maravilhas da vida: estudos sobre filosofia biológica ao alcance de todos ${ }^{38}$ (1904). O que não significa que Haeckel não divulgasse suas ideias sobre a filosofia biológica em palestras e textos curtos antes de 1892. Há um exemplo no período de produção de Nietzsche bem ilustrativo da postura do biólogo alemão. Haeckel retorna a Jena após uma viagem de sete meses ao Ceilão, três dias após a morte de seu querido amigo Darwin em 19 de abril de $1882 .{ }^{39}$ Em outubro do mesmo ano, no $55^{\circ}$ Encontro Anual da Sociedade de Naturalistas e Médicos Alemães, em Eisenach, ele faz uma emocionada conferência em homenagem ao naturalista inglês, na qual cantou um hino de devoção ao gênio

35 Richards (2008, p. 343) aponta uma forte influência da concepção de religião de Friedrich Schleiermacher não só em Haeckel, mas em toda sua família: a "religião do coração" como a verdadeira religião; a experiência da beleza; e a contemplação da natureza.

36 Cf. Haeckel, 1904, p.376.

37 Título original: Der Monismus als Band zwischen Religion und Wissenschaft.

38 Título original: Die Lebenswander: Gemainverständliche Studien über biologische Philosophie.

39 Cf. Richards, 2008, p. 349-353.

312 | Cad. Nietzsche, Guarulhos/Porto Seguro, v.42, n.1, p. 303-328, janeiro/abril, 2021. 
de Darwin e ao seu impacto no pensamento humano. A conferência foi publicada no mesmo ano: Sobre a concepção de natureza de Darwin, Goethe e Lamarck..$^{40}$ Para Haeckel, Darwin teria expandido as trilhas abertas por Lessing, Herder, Goethe e Kant. O naturalista inglês teria resolvido o problema kantiano da conformidade a fins: como um organismo direcionado a fins pode ter se originado sem a participação de causas finais. Além disso, a importância de Darwin pode ser dimensionada a partir de quatro feitos: a) a teoria darwiniana cumpriu as promessas do pensamento elevado alemão, especialmente Goethe; b) as teorias do desenvolvimento de Goethe, Lamarck e Darwin são vitais para a cultura; c) Darwin produziu uma filosofia social e moral que equilibra egoísmo e altruísmo ${ }^{41}$; e d) o pensamento darwiniano representa o triunfo da razão sobre os lacaios obscuros do antiprogresso e da superstição da Igreja Católica. O darwinismo, assim, substituiria a ortodoxia religiosa ou a Velha Fé pela religião de Goethe, isto é, uma religião monista da humanidade fundamentada no panteísmo. Para marcar ainda mais a oposição entre o darwinismo e a fé, Haeckel leu, durante a conferência pública, uma carta de Darwin a um aluno seu, o russo Nicolai Mengden, na qual o naturalista diz: "A ciência não tem nada a fazer com Cristo". ${ }^{42}$

De fato, vemos em um fragmento póstumo do inverno de 1880-1881, isto é, antes da morte de Darwin e da conferência de Haeckel em Eisenach, uma crítica contra as posições do biólogo alemão sobre a teoria do desenvolvimento de Darwin e sobre o monismo: "Haeckel: aceitar a disposição [Disposition], a teoria da descendência e a filosofia unitarista constitui o melhor critério para o grau de superioridade do espírito entre os homens: ele menciona

40 Título original: Über die Naturanschauung von Darwin, Goethe e Lamarck.

41 Sobre as críticas de Nietzsche contra a moral darwiniana, baseada no altruísmo e na compaixão, cf. Frezzatti, 2014, p. 112-123.

42 Cf. Richards, 2008, p. 350-352.

Cad. Nietzsche, Guarulhos/Porto Seguro, v.42, n.1, p. 303-328, janeiro/abril, 2021.| 313 
Frezzatti Jr., W. A.

os ingleses e os alemães: deixa de fora os franceses (Lamarck e Comte!" (Nachlass/FP 1880/1881, 8 [68], KSA 9.397). De alguma forma, não sabemos como, Nietzsche conhecia as propostas de Haeckel de uma filosofia biológica monista e da superioridade intelectual do pensamento darwiniano.

Embora fosse comum, na segunda metade do século XIX, a comparação de Darwin com Goethe, há dois versos de Nietzsche que podem indicar que o filósofo alemão tenha conhecido de algum modo a conferência de Haeckel em Eisenach. ${ }^{43}$ Trata-se dos fragmentos póstumos 28 [45] e [46] do outono de 1884, que são os seguintes:

Aos asnos alemães.

Esses bravos ingleses

Ao medíocre intelecto,

Tomais isto por "filosofia"?

Colocar Darwin ao lado de Goethe

Significa: lesar a majestade -

Majestatem genii!

De todos os espíritos medíocres

É o primeiro - o mestre.

De joelhos diante dele!

Colocá-lo mais alto

Significa - - -

(Nachlass/FP 1884, 28 [45], KSA 11.317-318) $)^{44}$

$43 \mathrm{Na}$ edição crítica de Colli e Montinari (KSA), não há nenhuma referência a isso.

44 Em alemão: “An die deutschen Esel.// Dieser braven Engeländer / Mittelmäßige Verständer / Nehmt ihr als „Philosophie“? / Darwin neben Goethe setzen / Heißt: die Majestät verletzen — / majestatem Genii! // aller mittelmäßigen Geister / Erster — das sei ein Meister, / und vor ihm auf die Knie! / Höher ihn herauf zu setzen / Heißt _ _ _ 
Saudações a vós, probos ingleses,

E a vosso Darwin, saudações, que ele

Entenda-vos tanto quanto seu gado!

Ingleses, tens razão em honrar

Vosso Darwin, ainda que ele não entenda

Nada mais do que criação de gado.

Apenas que - colocá-lo com Goethe

Significa lesar a majestade

Majestatem genii!

(Nachlass/FP 1884, 28 [46], KSA 11.318). ${ }^{45}$

\begin{abstract}
Entre os asnos alemães, podemos incluir a Leptodactylus haeckeli": "Hellwald, Haeckel e companhia - eles têm a disposição [Stimmung] dos especialistas e uma sabedoria de olfato de rã" (Nachlass/FP 1881, 11 [299], KSA 9.556) ${ }^{47}$. Vemos pelo restante
\end{abstract}

45 No texto original: "Heil euch, biedere Engländer / Eurem Darwin heil, verständ er / Euch so gut wie als sein Vieh! // Billig ehrt ihr Engeländer / Euren Darwin hoch, verständ er / Auch nicht mehr als Zucht von Vieh. // Nur — zu Goethen ihn zu setzen / Heißt die Majestät verletzen / Majestatem genii!".

46 Leptodactylus é um dos gêneros das rãs. A espécie Leptodactylus haeckeli é uma criação nossa para nos referirmos ao próprio Haeckel.

$47 \mathrm{O}$ historiador e geógrafo austríaco Friedrich Heller von Hellwald abordava a história da humanidade a partir de uma perspectiva darwinista. Em História da cultura em seu desenvolvimento natural desde os tempos mais antigos até o presente (Culturgeschichte in ihrer natürlichen Entwicklung von den ältesten Zeiten zur Gegenwart, 1875), Hellwald afirma que a religião e a moral são tão importantes para a luta pela existência quanto os outros recursos vitais e defende que o direito do mais forte é uma lei natural (cf. Weikart, 2004, p. 34, 81 e 168-170). Assim, a guerra é uma necessidade justificada pela luta pela existência de Darwin, e a violência é fonte primordial de toda a lei. A ciência e o progresso substituem a moralidade e a compaixão. Nietzsche cita Hellwald também em Nachlass/FP 1875, 5 [58], KSA 8.56, e 1885, 39 [21], KSA 11.627. Este último é apenas um lembrete: "Hellwald, Naturgeschichte des Menschen / Herman Müller / Burmeister Sobre Planta". História natural dos homens é uma obra de Hellwald de 1885. Burmeister é um naturalista alemão que realizou grande parte de seu trabalho na América do Sul, tendo se naturalizado argentino. No primeiro fragmento, Nietzsche faz uma crítica à teleologia na história e na ciência, atribuindo essa visão na Alemanha a Hegel. A discordância com Hellwald também é explícita. Contra o progresso, o filósofo alemão declara que a história não tem sentido. 
do fragmento que o olfato de rã é uma metáfora para a erudição do especialista, daquele que vê do mundo apenas aquilo que foi treinado a ver e que considera seu ponto de vista capaz de explicar toda a realidade e seu movimento, a Wirklichkeit. ${ }^{48}$ Além disso, é apenas um colecionador de dados, um arquivista. Não é à toa que Nietzsche, no mesmo fragmento, relaciona Haeckel com o teólogo David Strauss.

\section{Haeckel: um filisteu da formação}

O evolucionismo presente em A velha e nova fé $\mathrm{e}^{49}$ (1872) tem uma forte presença haeckeliana e não apenas darwiniana. A parte restante do fragmento póstumo citado logo acima é a seguinte:

A pequena partezinha de cérebro que está aberta ao conhecimento de seu mundo não tem nada o que produzir com sua totalidade, é um talentinho marginal, como quando alguém desenha ou toca piano; eles me fazem lembrar o velho honesto David Strauss, aquele que conta, com toda inocência, que devemos somente nos beliscar e beliscar outra vez para determinar se ainda temos sentimento de existência geral. Esses especialistas não o têm e são, por isso, tão "frios"; camelos da formação [Bildungskamele], em suas corcovas assentam-se muitos bons conhecimentos e informações, sem impedir que o conjunto seja nada mais que um camelo. (Nachlass/FP 1881, 11 [299], KSA 9.556)

A erudição valoriza artes menores e secundárias, confunde sensações empíricas com a essência das coisas e arquivam fatos em suas corcovas e os consideram as coisas mais valiosas. Essas são características do filisteu da formação (Bildungsphilister) apresentadas na I Consideração Extemporânea: David Strauss, o

48 A metáfora da perspectiva de rã como algo raso, mesquinho e limitado aparece em outros textos, tais como Assim falava Zaratustra (Za/ZA III, Do passar além, KSA 4.222-226) e Além de bem e mal (JGB/BM 2, KSA 5.16-17). Talvez a metáfora tenha a ver com a velha lenda chinesa dos sapos que viviam no fundo de um profundo poço.

49 Título original: Der alte und der neue Glaube.

316 | Cad. Nietzsche, Guarulhos/Porto Seguro, v.42, n.1, p. 303-328, janeiro/abril, 2021. 
confessor e o escritor. E David Strauss é o protótipo do filisteu da formação, e, do mesmo modo que Haeckel, suas obras eram muito lidas e bastante discutidas na Alemanha da segunda metade do século XIX. Na Primeira Extemporânea, o filisteu da cultura é o antípoda do genuíno homem de cultura, do artista. Haeckel e Strauss acreditavam que eram valorosos representantes da cultura, que sua formação (Bildung) seria a completa expressão da autêntica cultura alemã e que eram gênios, mas eles não eram criadores e sim imitadores de pretensas obras de arte e clássicos. Nietzsche vê o pensamento filisteu como a apoteose do lugar comum, a racionalização de todas as esferas da vida e o nivelamento de todas as coisas. Talvez Nietzsche também estivesse pensando em Haeckel quando afirma que o filisteu apenas atualiza seu mestre, no caso Darwin, tornando-o ao gosto decadente predominante, e que, para isso, pode criar poesias, músicas e até mesmo filosofias (cf. DS/Co. Ext. I 2, KSA 1.164-173). O conhecimento da natureza, ao lado do histórico, também é popularizado, como fez Haeckel com o Darwinismus: "nós [os filisteus] procuramos expandir nosso conhecimento sobre a natureza, para os quais não há falta de recursos compreensíveis para todos" (DS/Co. Ext. 4, KSA 1.178).

Em Schopenheuer como educador, a formação distinta da educação erudita e a ausência de "armadilhas patrióticas" e de obediência ao Estado fazem parte das condições para o nascimento do gênio filosófico, no entanto o filisteu é nacionalista, entusiasta do Estado (cf. SE/Co. Ext. III 8, KSA 1.411-427). Haeckel coloca sua própria erudição e a formação universitária a serviço do Estado. Ao receber Bismarck na Universidade de Jena, em julho de 1892, proclamou: "Enquanto o ribombar dos canhões na Batalha de Königgrätz em 1866 anunciava a queda do antigo Regime Federal Alemão e o início de um novo esplêndido período na história do Reich alemão, aqui em Jena nascia a história do 
Frezzatti Jr., W. A.

phylum [Stammesgeschichte]". ${ }^{50} \mathrm{O}$ biólogo alemão entendia que o novo estado prussiano era o produto histórico de lutas e seleção natural de um povo com integridade racial: o phylum. No mesmo discurso, ele propôs que fosse criado o título de Doutor em Filogenia e que fosse feita imediatamente a primeira concessão ao chanceler de ferro: como ninguém objetou, Haeckel proclama Bismarck "o primeiro e maior doutor em filogenia". ${ }^{51}$

\section{Ciência e docência livres: a questão do evolucionismo científico no currículo universitário alemão}

Certamente, uma das preocupações de Nietzsche com a formação filisteia incidia sobre o currículo das instituições de nível superior. E, provavelmente, ele tinha conhecimento da disputa entre Rudolf Virchow e Haeckel sobre a inclusão do evolucionismo nos currículos. ${ }^{52}$ Em uma conferência de 22 de setembro de 1877 , em Munique, intitulada "A liberdade da ciência na vida do Estado moderno", 53 Virchow fala sobre a guerra Franco-Prussiana e a Comuna de Paris, e, nesse contexto, ataca a teoria da descendência em três frentes: seu perigo político, sua confusão epistemológica e sua prevaricação pedagógica. Seus perigos assentavam-se sobre a permissão de uma teorização irrestrita, o que seria comprovado pelos acontecimentos trágicos na França em 1871: numa época em que a teoria da evolução ainda não tinha se consolidado como científica e era vista como uma mera especulação, o darwinismo era associado ao socialismo e ao comunismo, especialmente à sua face revolucionária e subversiva. A conferência do médico polonês era uma resposta às

50 Haeckel apud Gasman, 2017, p. 18.

51 Cf. Gasman, 2017, p. 19 e Desmond; Moore, 1995, p. 562-563.

52 Sobre a disputa Virchow-Haeckel, cf. Richards, 2008, 318-327.

53 Título original: Die Freiheit der Wissenschaft im modernen Staatsleben.

318 | Cad. Nietzsche, Guarulhos/Porto Seguro, v.42, n.1, p. 303-328, janeiro/abril, 2021. 
conferências anteriores de Haeckel e Karl von Naegeli ${ }^{54}$ e pedia a exclusão do evolucionismo dos currículos. Não se podia, segundo Virchow, ensinar algo que não havia sido confirmado pela ciência. Ademais, a teoria da descendência trazia em seu bojo a geração espontânea e a origem do homem a partir de animais inferiores. Essa teoria deveria ser investigada, mas ainda não poderia ser ensinada. $\mathrm{O}$ médico polonês fez ainda um ataque direto a Haeckel: "Quando Sr. Haeckel diz que é uma questão pedagógica se agora alguém coloca a teoria da descendência na base da educação e aceita a alma do plastídio ${ }^{55}$ como o fundamento de toda natureza mental, se alguém deve seguir a filogenia do homem até os tipos inferiores de vida, mesmo abaixo da geração original, então eu penso que isso é abandonar a tarefa pedagógica". ${ }^{56}$ Para Virchow, não poderíamos considerar como descoberta científica o pressuposto que os homens descendem de macacos ou de outros animais, e, por isso, não poderíamos ensinar a teoria do desenvolvimento nas universidades.

A crítica foi muito dura a Haeckel, pois ele tinha sido aluno de Virchow e era seu amigo. Sua resposta vem na forma de um livro, Ciência livre e docência livre ${ }^{57}$ (1878), no qual o biólogo alemão defende a teoria do desenvolvimento, especialmente do homem, argumenta que não podemos abrir mão das teorias especulativas na ciência e recusa a ideia de que o darwinismo apoiaria o socialismo, já que a igualdade dos indivíduos seria impossível, como mostrava a teoria da descendência. ${ }^{58}$ Haeckel era contrário a transportar teorias científicas para a prática política sem considerações éticas

54 Naegeli: biólogo e botânico suíço descobridor dos cromossomos.

55 Plastídio (Plastide) é o nome geral que Haeckel dá para a célula primitiva.

56 Virchow apud Richards, 2008, p. 323.

57 Título original: Freie Wissenschaft und freie Lehre.

58 Havia, nessa época, socialistas que acreditavam que o darwinismo seria adequado ao socialismo, pois a luta pela existência levaria ao melhoramento do homem e de sua condição social. Por exemplo, August Bebel, Karl Kautsky e Eduard Bernstein. 
Frezzatti Jr., W. A.

e filosóficas e tinha firmes convicções acerca das consequências sociais e morais do Darwinismus. Talvez a transformação do Nachlass/FP 1875, 12 [22] (KSA 8.257-259) no aforismo MA I/HH I 224 (KSA 2.189-193) reflita um certo alinhamento de Nietzsche a Virchow, especialmente em relação às consequências intelectuais das ideias de Darwin.

No entanto, em Schopenheuer como educador, Nietzsche posiciona-se firmemente contrário ao apoio do Estado à filosofia, pois não teríamos uma verdadeira liberdade da docência: "Vista mais precisamente, essa 'liberdade', com a qual o Estado atualmente [...] agracia alguns homens em favor da filosofia, é somente um ofício que alimenta seu empregado [...] Ao menos enquanto ele for favorecido e empregado, ele deve ainda reconhecer algo superior à verdade, o Estado" (SE/Co. Ext. III 8, KSA 1.413-415). E não apenas o Estado, mas sua religião, sua ordem social e sua organização militar. O Estado favorece apenas aqueles filósofos dos quais não tem medo. Embora a defesa da liberdade de ensino e a ideia da impossibilidade da igualdade dos indivíduos pudessem colocar Nietzsche ao lado da proposta de Haeckel, a rejeição de suas teorias biológicas, com suas consequências culturais associadas ao progresso, e sua estreita associação ao filisteísmo da formação fazem com que o biólogo seja suspeito aos olhos do filósofo. Além disso, no fragmento póstumo de 1875 mencionado acima, Nietzsche recusa fortemente a visão de Haeckel que considerava o desenvolvimento humano como integrante do desenvolvimento geral dos seres vivos. Para Nietzsche, podemos entender, Haeckel não ameaçava o Estado e não se opunha efetivamente à sua influência sobre as universidades. Desse modo, esse debate poderia ter contribuído para Nietzsche atribuir a Haeckel o olfato de rã. 


\section{Rütimeyer contra Haeckel}

Acreditamos que o contato de Nietzsche com as ideias do anatomista e zoólogo suíço Ludwig Rütimeyer, mais próximas da transmissão dos caracteres adquiridos e da ação direta do meio que da luta pela existência e da seleção natural, acirraram ainda mais suas críticas contra Haeckel. Os textos do zoólogo suíço são também uma das fontes do antidarwinismo do filósofo alemão.$^{59}$ As críticas de Rütimeyer contra o biólogo alemão estão para além das discordâncias teóricas, porque envolvem acusações de fraude, o que não passou despercebido por Nietzsche, como mostra um fragmento póstumo de 1884: "Eu presumo memória e uma espécie de espírito [Geist $]$ em todo o orgânico: o aparato é tão sutil que ele parece não existir para nós. A tolice de Haeckel, fazer dois embriões como iguais! Não se deve deixar enganar pela pequenez - o orgânico não surgido" (Nachlass/ FP 1884, 25 [403], KSA 11.117). Rütimeyer acusou Haeckel de usar três vezes a mesma gravura de embrião ${ }^{60}$ Em um de seus principais livros, História natural da criaçã o ${ }^{61}$ (1868), o biólogo alemão utiliza ilustrações das fases iniciais de embriões, inclusive humano, para mostrar suas semelhanças morfológicas com o intuito de provar a lei biogenética. Todavia, parece que Haeckel não possuía embriões reais para servir de modelos a suas ilustrações. Rütimeyer acusa-o publicamente de copiar ilustrações de Theodor Bischoff e Alexander Ecker, ${ }^{62}$ numa resenha sobre dois textos do biólogo alemão publicada

59 Cf. Andler, 2016, p. 537-547 e Janz, 2016, p. 258-261.

60 Cf. Richards, 2008, p. 234-243 e 278-279.

61 Título original: Natürliche Schöpfungsgeschichte.

620 texto plagiado de Bischoff seria História do desenvolvimento do ovo canino (Entwicklungsgeschichte des Hunde-Eies, 1845), e de Ecker, Icones physiologicae (1851-1859). Outros cientistas também acusaram Haeckel de fraude, tais como Wilhelm His (Unsere Körperform und das physiologische Problem ihrer Entstehung, 1874), Alexander Goette e Albert von Kölliker (cf. Richards, 2008, p. 280-296). 
Frezzatti Jr., W. A.

em Archiv für Anthropologie em 1868: Sobre a origem e a árvore genealógica da linhagem humana ${ }^{63}$ e História natural da criação.

Haeckel, na primeira edição de História natural da criação, escreve: "Se você comparar o ovo do ser humano (fig. 5) com os do macaco (fig. 6) e do cão (fig. 7), você não será capaz de perceber a diferença [...] Se você comparar embriões jovens do cão, da galinha e da tartaruga nas figuras 9, 10 e 11, você não estará em posição de

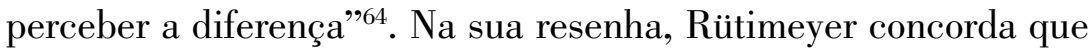
não se pode perceber a diferença, mas porque foi usada a mesma xilogravura três vezes! Ele também compara o livro de Haeckel com Telliamed, uma fábula que apresentava o desenvolvimento gradual do mundo e do homem: ${ }^{65}$ suas teorias são apenas fantasias. Wilhelm His também condenou Haeckel, quem havia "havia perdido o direito de ser considerado um cidadão da república dos cientistas sérios". ${ }^{66}$ Parece que Haeckel realmente havia cometido um erro, o qual seria corrigido na segunda edição do livro. Além disso, nesse livro e em outros, ele passa a indicar que as ilustrações eram baseadas em fontes publicadas. Darwin escreve ao biólogo alemão, consolando-o e lamentando Rütimeyer ser tão retrógrado, já que a disputa entre os dois não se limitava à questão do plágio: assim como His, Rütimeyer era radical em não aceitar a utilização da teoria do desenvolvimento para explicar a embriogênese.

63 Título original; Über die Entstehung und den Stammbaum des Menschengeschlechts.

64. Haeckel, 1868, p. 241 e 249.

65 Trata-se de uma obra inicialmente publicada de modo anônimo, Telliamed, ou Entrevistas de um filósofo indiano com um missionário francês (Telliamed, ou Entretiens d'un philosophe indien avec un missionaire François, 1748), escrito por Benoît de Maillet, que se baseou em suas investigações geológicas. Telliamed é seu sobrenome escrito ao contrário (cf. Richards, 2008, 278-279).

66 His, 1874, p. 171.

322 | Cad. Nietzsche, Guarulhos/Porto Seguro, v.42, n.1, p. 303-328, janeiro/abril, 2021. 
Nietzsche e Rütimeyer eram colegas na Universidade da Basileia, ${ }^{67} \mathrm{e}$, segundo Janz ${ }^{68}$, dificilmente o filósofo alemão teria tido acesso direto ao anatomista. Por outro lado, conforme Andler ${ }^{69}$, Nietzsche e Rütimeyer se juntavam regularmente aos colegas nos passeios de sábado à tarde na Basileia, e, quando a doença o impediu de participar em meados de 1876, seu amigo Franz Overbeck lhe levava o resultado das discussões. De qualquer forma, é certo que Nietzsche conhecia os escritos do zoólogo suíço, como mostra uma carta a Karl von Gersdorf de 08 de maio de 1875, recomendando a leitura de "A população dos Alpes" e Do mar aos Alpes. ${ }^{70}$

Além dessa carta, a admiração de Nietzsche ao colega pode ser vista em um fragmento póstumo de 1881, no qual afirma que as virtudes consideradas alemãs, a audácia interna e a resignação externa, são encontradas na sua expressão mais bela nos suíços, pois na Suíça as características alemãs estariam mais protegidas: "Qual poeta poderia se contrapor ao suíço Gottfried Keller? Haveria algum pintor que seja similar a Böcklin na busca de caminhos? Algum intelectual sábio similar a J. Burckhardt? A grande celebridade de Haeckel incomoda de algum modo a ainda maior solene glória de Rïtimeyer? - para nomear apenas alguns nomes importantes" (Nachlass/FP 1881, 11 [249], KSA 9.536).

67 Em 1865, Rütimeyer torna-se reitor dessa universidade.

68 Cf. Janz, 2016, p. 258.

69 Cf. Andler, 2016, p. 537-538.

$70 \mathrm{Na}$ carta, lemos: "No mesmo volume [do anuário dos clubes alpinos suíços], encontra-se um extraordinário artigo de Rütimeyer 'A população dos Alpes' de grande interesse; aconselho, também do mesmo erudito, (talvez haja algo em ambos escritos que seja como um presente para seu pai) $D o$ mar aos Alpes, Berna, 1854. Livraria Dalpsche" (Nietzsche, 2009, p. 67) (KSB 5.47-50). O primeiro texto, no original: "Die Bevölkerung der Alpen" (1864); o segundo: Vom Meer bis nach den Alpen (1854). Na biblioteca de Nietzsche, havia um exemplar de As transformações no reino animal na Suiça desde a presença de seres humanos (Die Veränderungen der Thielwelt in der Schweitz seit Anwesenheit der Menschen, 1875), também de Rütimeyer (cf. Andler, 2016, p. 547). 
Frezzatti Jr., W. A.

Portanto, o fragmento póstumo de 1884 sobre os embriões foi escrito possivelmente com a marca das críticas de Rütimeyer a Haeckel, e não apenas a acusação de fraude, mas também as objeções biológicas, talvez muito mais importantes, pois Nietzsche aponta que não bastam semelhanças anatômicas visíveis para tornar semelhantes os embriões, há toda uma série de características não visíveis que os tornaria muito diferentes, como, por exemplo, a memória.

Nietzsche, possivelmente, tinha em mente, ainda no mesmo fragmento, as implicações políticas da filogenia. Em História natural da criação, Haeckel não utilizava a lei biogenética apenas para provar a teoria da descendência: "O que devem os membros da aristocracia pensar sobre o sangue azul [Vollblutt] que flui através de suas artérias privilegiadas, quando eles aprendem que todos os embriões humanos, tanto o nobre quanto o de classe média, dificilmente podem ser distinguidos, nos dois primeiros meses de desenvolvimento, dos embriões caudatos de um cão ou de outros mamíferos?"71 Ainda aqui Nietzsche poderia indicar que as diferenças não seriam suficientes para serem visualizadas. Em Além de bem e mal, o filósofo alemão afirma que a física, e aqui podemos dizer o mesmo acerca da análise dos embriões, estaria baseada no empirismo ingênuo: aquilo que pode ser visto e tocado é considerado verdadeiro. $\mathrm{O}$ imperativo "onde o homem nada encontra para ver e pegar, aí ele nada tem a tratar" seria adequado a "uma linhagem trabalhadora rude de futuros maquinistas e construtores de pontes, os quais teriam apenas trabalho grosseiro a despachar" (JGB/BM 14, KSA 5.28-29).

71 Haeckel, 1868, p. 240.

324 | Cad. Nietzsche, Guarulhos/Porto Seguro, v.42, n.1, p. 303-328, janeiro/abril, 2021. 


\section{Considerações finais}

Acreditamos que esta investigação centrada nos fragmentos póstumos contra Haeckel nos permite afirmar que, apesar das poucas referências diretas, as críticas contra o biólogo alemão se inserem numa importante e complexa articulação do pensamento nietzschiano. Em outras palavras, a rejeição de Haeckel articula-se com as críticas contra o darwinismo e contra o filisteísmo, principalmente David Strauss. Nietzsche estava ciente das implicações da filosofia biológica de Haeckel e de suas relações com o contexto de sua época. Não se trata de uma simples implicância com um contemporâneo, mas de levantar-se contra o hegelianismo, contra o darwinismo, contra a ideologia do progresso, contra o cientificismo e contra a decadência da cultura. As críticas a Haeckel são um capítulo das críticas às ideias modernas. ${ }^{72}$

72 Como este artigo faz parte de um Festschrift em homenagem à profa. Scarlett Marton, devemos dizer que a relação do pensamento nietzschiano com a biologia do século XIX, um dos eixos de nossa pesquisa, foi apresentada a nós, pela primeira vez, por ela, por meio de seus textos e de suas aulas em meados da década de 1990. Lembro-me ainda de ter lido, por exemplo, sobre a construção da noção de vontade de potência: "Se Darwin sustentou que esta [a concorrência vital] existe entre os animais, Nietzsche afirma que está presente no próprio organismo. Ora, foi Wilhelm Roux quem lhe forneceu essa ideia. [...] Além do trabalho de Roux, Nietzsche conheceu o tratado de Rolph sobre questões de biologia. Rolph tentou explicar a variação dos organismos por outra via: o ser vivo, alimentando-se, seria levado a absorver mais do que precisava, dada a sua insaciabilidade" (Marton, 2010, p. 56). A primeira edição desse importante livro, aquela lida por mim naquela época, é de 1990. 


\section{Nietzsche versus Haeckel}

Abstract: In Nietzsche's few explicit references to German biologist Ernst Haeckel, there is a clear rejection of his biological and cultural thinking. The aim of this article is to propose that, despite the small amount of direct mentions, Nietzsche's criticism of Haeckel constitute an intense antagonism between them and are part place of the context of Nietzschean censure against the German education (Bildung) and culture (Kultur) and against the metaphysical condition of science. The text presents four aspects of the antagonism between Nietzsche and Haeckel: Haeckel's Das Darwinismus; Haeckel's influence on David Strauss; the inclusion of scientific evolutionism in the curriculum in Germany; and the conflict between Ludwig Rütimeyer and Haeckel.

Keywords: Darwinismus, David Strauss, Development, Ernst Haeckel, Ludwig Rütimeyer.

\section{Referências}

ANDLER, Charles. Nietzsche: vida e pensamento. Tradução: R. Schöpke e M. Baladi. Rio de janeiro: Contraponto / PUC-Rio, 2016. v. I.

DARWIN, Charles R. The descent of man, and selection in relation to sex, vol. 1. London: J. Murray, 1871.

. Darwin Correspondence Project. Disponível em: < https://www. darwinproject.ac.uk/letter/DCP-LETT-4422.xml >. Acessado em 15/08/2018.

DE BEER, Gavin. Embryos and Ancestors. Oxford: Oxford University Press, 1940

DESMOND, Adrian; MOORE, James. Darwin: a vida de um evolucionista atormentado. Tradução de H. Santos, G. Pereira e Maria A. Gelman. São Paulo: Geração Editorial, 1995.

EMDEN, Christian J. Nietzsche's Naturalism: Philosophy and the Life Sciences in the Nineteenth Century. Cambridge: Cambridge University Press, 2014.

FONTES, Luiz Roberto; HAGEN, Stefano. Fritz, ou Frederico Müller: Nota sobre o sentido de brasilidade de Fritz Müller. In: MÜLLER, FRITZ. Para Darwin. Tradução de L. R. Fontes e S. Hagen. Florianópolis: UFSC, 2009. p. 277-279.

326 | Cad. Nietzsche, Guarulhos/Porto Seguro, v.42, n.1, p. 303-328, janeiro/abril, 2021. 
FREZZATTI Jr., Wilson A. Nietzsche contra Darwin. $2^{\text {a }}$ edição ampliada e revista. São Paulo: Edições Loyola, 2014.

GASMAN, Daniel. The scientific Origins of the of National Socialism. New York: Routledge, 2017. Visualisado em: < https://books.google.com.br/ books?id=UxwuDwAAQBAJ\&pg=PT90\&lpg=PT90\&dq=haeckel+bismarck+Jena\&source $=$ bl\&ots $=$ RK8BVMOIIX\&sig=V gD3KsmFc-LoTLeN37D67xPdNGc\&hl=pt-R\&sa=X\&ved=2ahUKEwjuwZ2X1PfcAhXDF5AKHR6jD08Q6AEwAHoECAkQAQ\#v=onepage\&q=Haeckel\%20 bismarck\%20Jena\&f=false $>$. Acessado em 18/08/2018.

HAECKEL, Ernst. Generelle Morphologie der Organismen: allgemeine Grundzüge der organischen Formen-Wissenschaft, mechanisch begründet durch die von $C$. Darwin reformirte Descendenz-Theorie. 2er bd. Berlin: Georg Reimer, 1866.

. Natürliche Schöpfungsgeschichte. Berlin: Georg Reimer, 1868. Disponível em: < http://www.deutschestextarchiv.de/book/show/haeckel_ schoepfungsgeschichte_1868 >. Acessado em 25/07/2020.

. Les merveilles de la vie - Études de philosophie biologique. Paris: Schleicher frères, èditeurs, 1904.

Die Lebenswunder: Gemeinverständliche Studien über biologische Philosophie. Leipzig/ Berlin: Alfred Kröner Verlag/ Carl Henschel Verlag, 1924.

HIS, Wilhelm. Unsere Körperform und das physiologische Problem ihrer Entstehung. Leipzig: F. C. W. Vogel, 1874. Disponível em: < https://books.google.com. br/books?id=moFEAQAAIAAJ\&printsec $=$ frontcover\&source $=$ gbs_ge summary_r\&cad $=0 \#_{v}=$ onepage $\& q \& f=$ false $>$. Acessado em 25/07/2020.

JANZ, Curt P. Friedrich Nietzsche: Uma biografia. v. I. Tradução: Markus A. Hediger. Petrópolis: Vozes, 2016.

LACERDA, João Baptista de. Fritz Müller. Archivos do Museu Nacional, Rio de Janeiro, v. 10, 1899. p. XIII-XV. In: MÜLLER, FRITZ. Para Darwin. Tradução de L. R. Fontes e S. Hagen. Florianópolis: UFSC, 2009. p. 273-276.

MARTON, Scarlett. Nietzsche: Das forças cósmicas aos valores humanos. $3^{\mathrm{a}} \mathrm{ed}$. Belo Horizonte: Editora UFMG, 2010. 
Frezzatti Jr., W. A.

MAYR, Ernst. O desenvolvimento do pensamento biológico. Trad. de I. Martinazzo. Brasília: Editora da UnB, 1998.

MOORE, Gregory. Nietzsche, Biology and Metaphor. Cambridge: Cambridge University Press, 2002.

NIETZSCHE, Friedrich W. Sämtliche Werke. Kritische Studienausgab. G. Colli und M. Montinari (Hg). Berlin: Walter de Gruyter, 1999. 15 Bd. (KSA)

Correspondencia: enero 1875 - diciembre 1879. Traducción: Andrés Rubio. Madrid: Trotta, 2009.

RICHARDS, Robert J. The Tragic Sense of Life: Ernst Haeckel and the Struggle over Evolutionary Thought. Chicago: University of Chicago, 2008.

ROUX, Wilhelm. Der Kampf der Theile im Organismus: ein Beitrag zur Vervollständigung der mechanischen Zweckmässigkeitlehre. Leipzig: Verlag von Wilhelm Engelmann, 1881.

RUSSELL, Edward S. Form and Function: A Contribution to the History of Animal Morphology. London: J. Murray, 1916.

SPENCER, Herbert. The Principles of Biology. v. I. London: Williams and Norgate, 1864.

. First Principles. $2^{\text {nd }}$ ed. London: Williams and Norgate, 1867.

WEIKART, Richard. From Darwin to Hitler: Evolutionary Ethics, Eugenics, and Racism in Germany. New York: Palgrave Macmillan, 2004.

Enviado: 03/09/2020

Aceito: 29/11/2020 